WellBeing International

WBI Studies Repository

$11-2012$

\title{
The Moral Status of Invasive Animal Research
}

Bernard E. Rollin

Follow this and additional works at: https://www.wellbeingintlstudiesrepository.org/acwp_arte

Part of the Animal Experimentation and Research Commons, Animal Studies Commons, and the Bioethics and Medical Ethics Commons

\section{Recommended Citation}

Rollin, B. E. (2012). The moral status of invasive animal research. Hastings Center Report, 42(s1), S4-S6.

This material is brought to you for free and open access by WellBeing International. It has been accepted for inclusion by an authorized administrator of the WBI Studies Repository. For more information, please contact wbisr-info@wellbeingintl.org.

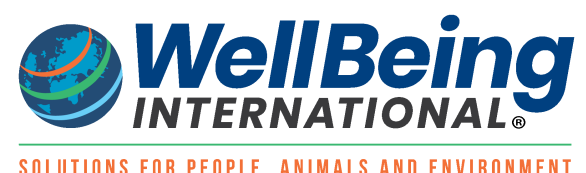




\title{
The Moral Status of Invasive Animal Research
}

\author{
Bernard E. Rollin
}

During the 1970s and 1980s, two veterinarians and I conceptualized, drafted, and ultimately, in 1985, persuaded Congress to pass federal legislation assuring some minimal concern on the part of researchers for the welfare of laboratory animals. ${ }^{1}$ As part of that activity, I had occasion to study the scientific community's attitude toward the ethical issues emerging from the use of animals in biomedical research. I searched the scientific literature for an explicit articulation of the moral position underlying such use, but I found nothing save for an occasional gnomic statement such as, "Animal research is not a moral issue; it is a scientific necessity"-as if it could not be both. I came to see the failure of the scientific community to engage that issue as an inevitable consequence of what I have called "scientific ideology," or "the common sense of science," which is to science what ordinary common sense is to daily life. ${ }^{2}$

This ideology rests on two assumptions. One of them is that science is "value free" in general and "ethics free" in particular-that science, which concerns only what is observable or empirically testable, has no place for ethical judgments. The second is that scientists must be agnostic about consciousness (and pain) in animals. This assumption explains how it was possible that a literature search I performed in 1982 with the Library of Congress on "analgesia for laboratory animals" unearthed only two references, one of which merely affirmed that there ought to be papers on the subject. The ubiquity of the "common sense of science" ideology was dramatically illustrated when James B. Wyngaarden-then the director of the National Institutes of Health, arguably the chief biomedical scientist in the United States, and, therefore, science's principal spokesperson-was reported as saying that "ethical issues such as gene sequencing are always controversial, but research should not be hampered by moral considerations." ${ }^{3}$

Scientists, like any other subgroup of society, must operate within the boundaries of the consensus social ethic at a given historical moment or else risk loss of autonomy at the hands of restrictive social regulation or legislation. Our laws for research animals passed, despite very vigorous opposition from the research community, because they accorded well with burgeoning societal concern about the welfare of animals used for social benefit. In essence, the research community had failed to meet societal expectations for the proper treatment of research animals. A commitment to such treatment, particularly control of pain, should have been part of researchers' professional ethics.

Even today, it is doubtful that animal researchers understand the social expectations regarding animal care and use. Historically, society has not had a robust, institutionalized ethic for how animals should be treated. Before the Animal Welfare Act, the only laws constraining animal use in society were the anticruelty laws forbidding sadistic, deviant, purposeless, deliberate, unnecessary infliction of pain and suffering on animals, or outrageous neglect. These laws, both by statute and by judicial interpretation, did not apply to socially accepted animal uses such as research or agriculture. Because the overwhelming use of animals in society was in agriculture, aimed at providing food, fiber, locomotion, and power, and because the key to agricultural success was having healthy animals, good husbandry and good care were enforced by the most powerful sanction, self-interest; the anticruelty laws were only there for society to manage sadists and psychopaths unmoved by self-interest. But with the emergence of new kinds of "normal" animal use-such as intensive agriculture and animal research, both of which caused animal pain and suffering that did not fall under the anticruelty ethic-society was forced to create a new ethic for 
animals that went "beyond cruelty." The Animal Welfare Act was a start, but it did not address all of the ethical concerns that society has had about the treatment of animals. As evidence of the need for a new ethic for animals, thousands of bills pertaining to animal welfare have been promulgated across the United States in the last decade.

The new ethic for animals essentially applies much of our social ethic for humans, mutatis mutandis, to the treatment of animals and embodies the desired protections in the legal system. There are three layers of ethical concern regarding invasive research on animals:

1. What entitles humans to use animals in ways that harm, hurt, kill, or distress them in research for human benefit? We cannot use humans-even socially disvalued human beings such as prisoners, mentally impaired persons, and unwanted children - for the benefit of the majority or of society as a whole without making sure that they understand the research and participate in it willingly. The researchers responsible for the Tuskegee experiments on untreated syphilis in black men argued that such people were "worth less" than other citizens, and thus, their interests could be sacrificed, without their informed consent, for the good of the majority. ${ }^{4}$ But any such position was categorically rejected when the study came to light during the 1970s, prompting detailed federal restrictions on the use of human subjects in research. So what are the arguments for using animals in these ways?

2. The only plausible argument for using human beings in these ways is the utilitarian one that they generate more benefits than costs. Society has categorically rejected that claim. But perhaps, in the case of animals, such an argument is socially acceptable. If so, we are led to another ethical concern about the use of animals in scientific experimentation. If the only justification for it is the benefit it provides-and that this benefit far outweighs the cost to the animals-then it follows that the only allowable animal use in experimentation would be that it provides greater benefit than the cost to the animals. But this is clearly not the current state of affairs. Animals are deployed in painful ways in myriad experiments that do not provide significant benefit. These experiments range from toxicological experiments that only provide some legal protection for corporations from lawsuits regarding product liability, to experiments in pursuit of new weaponry, to psychological experiments designed to inflict learned helplessness on animals as a model for human depression (illegal in the United Kingdom), to seeing how many bites an "intruder" animal into an established animal colony sustains, to numerous other experiments augmenting knowledge that appears to be of no practical value. ${ }^{5}$

3. Given that practitioners of animal research essentially disregard the previous two ethical concerns, we are left with a third. If researchers fail to attend to the question of our right to use animals in invasive ways and ignore the clear-cut moral demand that the benefits from the research outweigh the costs to the animals, at the very least common sense and common decency dictate that animals used in research should be treated as well as possible. But even if, as the research community claims, the vast majority of experiments performed on animals do not cause significant pain, 100 percent of research animals suffer because the environments in which they are kept fail to respect their biological and psychological needs and natures. Social animals are kept in isolation; nocturnal animals are kept in twenty-four-hour-a-day light; housing and husbandry conditions are designed in accordance with human convenience, not animals' needs. Cage design is primarily determined by ease of cleaning, not animal comfort. Appallingly, even the death of the animals in the service of research is not the most painless and comfortable death possible. The vast majority of animals "euthanized" for research purposes do not get a "good death"; asphyxiation or suffocation by inhaled carbon dioxide is by no stretch of the imagination humane, despite its being approved by the American Veterinary Medical Association. AVMA is ostensibly the arbiter of humaneness of euthanasia, but its track record shows greater concern for human convenience than for animal welfare. 
The only reference in the law to the many ways that animals used in research can suffer beyond the infliction of physical pain upon them-including fear, anxiety, separation from family and other animals of the same species, unnatural diets and food acquisition, severely truncated possibility of movement, denial of opportunities for play, disturbance of routine-is the statutory requirement that pain and distress be controlled. "Distress" is both a catch-all term and a placeholder for better understanding of the varied and subtle ways that animals used in laboratories can be harmed. Given the ideological resistance researchers have shown to even acknowledging physical pain in research animals, little progress on "distress" has been made by the animal research community.

The overwhelming majority of attention paid to ethical issues in category three has been devoted to control of acute physical pain and development of analgesic regimens. Little progress has been made in relieving chronic pain and in the control of any pain in farm animals used in research, since the Animal Welfare Act excludes agricultural animals. But an adequate account of animal ethics must transcend exclusive concern with pleasure and pain and recognize the full range of possible "matterings" unique to different sorts of animals. To accomplish this, we must look to Aristotle, the greatest common-sense philosopher of the ancient world, and specifically to his concept of telos, or animal nature, a root notion of his functional, teleological biology. Whereas modern biology focuses on reductionist, molecular, and mechanistic explanations, Aristotle's biology emphasizes the unique set of traits and powers that make the animal what it is - the "pigness" of the pig, the "dogness" of the dog.

Aristotle recognized that different animals evidenced different ways of fulfilling the fundamental nature of living things, such as nutrition, locomotion, sensation, cognition, and reproduction. How an animal fulfills these functions is what constitutes its nature. Secondary school biology is still studied in the Aristotelian way. There is nothing mystical about telos; it is simply what common sense recognizes as "fish gotta swim, birds gotta fly." The only departure that must be made from Aristotle today is to see teloi not as fixed and immutable, but as slices or snapshots of a dynamic process of evolution, genetically encoded and environmentally expressed.

An example from coyote behavior strikingly illustrates how telos needs can trump even major physical pain. It has been recounted for years that coyotes, caught in a leg-hold trap, will chew their legs off, enduring terrible pain, rather than submit to immobility. (This is also true for other animals, such as raccoons.) This is understandable given the coyote's telos as a free-ranging predator (or, on occasion, prey). It is not plausible to suggest that the animal chews its leg off to avoid death, since it is not possible that a nonlinguistic being has a concept of death, though it understands the inability to escape. Clearly, the animal is not chewing the leg in order to escape the pain, as any attempt to chew the leg off will greatly increase the pain.

Novelty of any sort evokes stress in most if not all animal teloi. Researchers know that animals can be trained by reward to willingly accept some physically painful experimental procedures. In one instance, a friend of mine was drawing blood from dogs daily for a vaccine study. She would enter the facility, play with each dog, draw the blood, and then give the dog a treat. On one occasion, one of the dogs set up such a howl as she was leaving that she raced back to see if his paw was caught in the cage door. It turned out she had forgotten to draw blood from that dog, and he had missed his play and his treat, which bothered him more than the blood draw. Such examples illustrate three major points:

1. Pain, as a physical phenomenon, does not begin to capture all the ways that what we do to animals matters to them.

2. Other things we do to animals can be worse for them than physical pain. Unfortunately, we have no words for many of the myriad ways we can harm or cause animals to suffer. 
3. In general, interfering with or impeding actualization of telos creates a negative experiential state for an animal.

In sum, and in spite of the laws, the animal research community has been remiss in failing to address all three levels of ethical concern emerging from animal research. It is unlikely that society will force researchers to address the first level—namely, whether there is any moral justification for using animals in research. Restricting invasive animal use to what is patently beneficial will probably evolve in time, but very slowly, since such an evolution will depend in part on the creation of non-animal alternatives. But the third level of ethical concern-providing animals with the best possible living conditions compatible with their natures and eliminating negative conditions-is currently practicable. Attention not only to physical needs and control of physical pain, but also to accommodating animal telos in a manner that eliminates all forms of "negative mattering" for the animals and provides occasions for "positive mattering"-what we may call "animal happiness"-can go a long way toward making animal research a moral science. Inevitably, a research environment that makes the life of an animal used in research a pleasant one can do a great deal to counterbalance the issues that arise from invasive animal use.

\section{NOTES}

1. B.E. Rollin, "The Regulation of Animal Research and the Emergence of Animal Ethics: A Conceptual History," Theoretical Medicine and Bioethics, 27 (2006): 285-304.

2. B.E. Rollin, Science and Ethics (New York: Cambridge University Press, 2006).

3. P. West, "Director Addresses Health Research," The State News, February 27, 1989.

4. This was in fact communicated to me in a private conversation by one of the members of the Tuskegee research team. The Nazis presupposed such a principle in their research on unwilling subjects.

5. B.E. Rollin, Animal Rights and Human Morality (New York: Prometheus Books, 1992), 141-46 and 149-51; T. Hartung, "Toxicology for the Twenty-First Century," Nature 460 (2009): 208-212. 